\title{
Unravelling the environmental drivers of deep-sea nematode biodiversity and its relation with carbon mineralisation along a longitudinal primary productivity gradient
}

\author{
E. Pape ${ }^{1}$, T. N. Bezerra ${ }^{1}$, D. O. B. Jones ${ }^{2}$, and A. Vanreusel $^{1}$ \\ ${ }^{1}$ Marine Biology Research Group, Krijgslaan 281/S8, 9000 Ghent, Belgium \\ ${ }^{2}$ National Oceanography Centre, European Way, Southampton SO14 3ZH, UK \\ Correspondence to: E. Pape (ellen.pape@ugent.be)
}

Received: 29 November 2012 - Published in Biogeosciences Discuss.: 20 December 2012

Revised: 7 April 2013 - Accepted: 19 April 2013 - Published: 8 May 2013

\begin{abstract}
Alongside a primary productivity gradient between the Galicia Bank region in the Northeast Atlantic and the more oligotrophic eastern Mediterranean Basin, we investigated the bathymetric $(1200-3000 \mathrm{~m})$ and longitudinal variation in several measures for nematode taxon (ShannonWiener genus diversity, expected genus richness and generic evenness) and functional diversity (trophic diversity, diversity of life history strategies, biomass diversity and phylogenetic diversity). Our goals were to establish the form of the relation between diversity and productivity (measured as seafloor particulate organic carbon or POC flux), and to verify the positive and negative effect of sediment particle size diversity (SED) and the seasonality in POC flux (SVI), respectively, on diversity, as observed for other oceanographic regions and taxa. In addition, we hypothesised that higher taxon diversity is associated with higher functional diversity, which in turn stimulates nematode carbon mineralisation rates (determined from biomass-dependent respiration estimates). Taxon diversity related positively to seafloor POC flux. Phylogenetic diversity (measured as average taxonomic distinctness) was affected negatively by the magnitude and variability in POC flux, and positively by SED. The latter also showed an inverse relation with trophic diversity. Accounting for differences in total biomass between samples, we observed a positive linear relation between taxon diversity and carbon mineralisation in nematode communities. We could, however, not identify the potential mechanism through which taxon diversity may promote this ecosystem function since none of the functional diversity indices related to both diversity and nematode respiration. The present results sug-
\end{abstract}

gest potential effects of climate change on deep-sea ecosystem functioning, but further also emphasise the need for a better understanding of nematode functions and their response to evolutionary processes.

\section{Introduction}

Biodiversity within deep-sea sediments exhibits clear geographic variation. Potentially simultaneously acting drivers of variation in local diversity include productivity, boundary constraints, sediment heterogeneity, oxygen availability, hydrodynamic regimes and catastrophic physical disturbance (Levin et al., 2001). Gradients in these environmental factors co-determine local diversity by influencing the rates of local processes like resource partitioning, competition, predation, physical disturbance, etc. Bathymetric variation in diversity is one of the most studied geographical diversity trends (e.g. Danovaro et al., 2008b; Rex and Etter, 2010; Tecchio et al., 2011). Benthic diversity generally shows a hump-shaped bathymetric pattern, with a peak around 1500-2500 m depth (Rex and Etter, 2010; Stuart et al., 2003). However, the unimodal relationship between diversity and water depth is not universal and the form of the association varies between regions (Danovaro et al., 2010; Stuart et al., 2003). The depth-related gradient in diversity is believed to be governed by productivity (i.e. the particulate organic carbon (POC) flux) and/or sediment characteristics (Gray, 2002; Stuart et al., 2003). Deep-sea diversity has been documented to vary positively (Glover et al., 2002; 
Lambshead et al., 2000, 2002), negatively (Gooday et al., 2012) or unimodally (Leduc et al., 2012a; McClain et al., 2012; Tittensor et al., 2011) with productivity for different taxa and geographic regions. These differences in diversityproductivity trends may be related to the differential productivity ranges considered (Rex and Etter, 2010). A unimodal curve may only be found when the range of productivity is sufficiently large, whereas a positive and linear relation may be retrieved under a low- and high-productivity regime, respectively. The magnitude of productivity is assumed to have a positive effect on diversity (through the stimulation of population growth), whilst temporal variability in productivity may depress diversity (by limiting feeding to certain periods of the year) (Chown and Gaston, 1999). Seasonality in surface productivity had an adverse effect on foraminiferal species diversity in abyssal sediments (Corliss et al., 2009; Gooday et al., 2012). The diversity of sediment particles, which can be regarded as a measure of habitat heterogeneity, has a positive influence on macrofaunal (Etter and Grassle, 1992) and nematode (Leduc et al., 2011) species diversity in the western North Atlantic and in the Pacific Ocean, respectively.

As a consequence of the worldwide ongoing decline in marine and terrestrial biodiversity (Pereira et al., 2010), there has been an explosion in the number of studies addressing the effect of biodiversity on the functioning of ecosystems (reviewed by Balvanera et al., 2006; Hooper et al., 2002; Stachowicz et al., 2007). There are four main possible impact scenarios of biodiversity on an ecosystem function: (1) no effect (null model); (2) all taxa (species/genera, etc.) contribute to ecosystem functioning (rivet hypothesis); (3) there is a minimum need of species, and all other species are redundant (redundancy model); (4) the effect is not predictable (idiosyncratic model) (Lawton, 1994; Naeem et al., 1995) According to different authors, the nature and strength of the relation between diversity and an ecosystem function depends on the environmental factors that drive diversity and ecosystem processes (Bengtsson et al., 2002; Cardinale et al., 2000) and the ecosystem function considered (Bolam et al., 2002; Hiddink et al., 2009; Naeem et al., 1995).

Numerous biodiversity-ecosystem function studies related taxon diversity (i.e. the diversity of taxa, with taxa indicating species, genera or other taxonomic levels), and primarily taxon richness (i.e. the number of taxa), to the rate of ecosystem processes, assuming this diversity measure serves as an adequate surrogate for functional diversity (Naeem and Wright, 2003). However, taxa may differ in their contribution to total functional diversity (degree of redundancy and singularity) and/or total abundance (commonness-rarity), resulting in a huge variety in possible relationships between taxon and functional diversity (Cadotte et al., 2011; Naeem and Wright, 2003). Moreover, the nature of the relation between taxon and functional diversity depends on the measure of functional diversity employed (Naeem and Wright 2003). Analogous to taxon diversity, different aspects of functional diversity can be measured - namely richness, divergence and evenness (Mason et al., 2005). Numerous univariate and multivariate indices have been developed that fall into one of these categories (Weiher, 2011). Because functional diversity provides a direct mechanistic link between diversity and ecosystem functioning, a growing amount of research has been devoted to the effect of functional - instead of taxon diversity on ecosystem functioning (Díaz and Cabido, 2001; Petchey et al., 2004; Reiss et al., 2009). In many studies where both functional and taxon diversity were related to the rate of ecosystem processes, functional diversity or composition explained a greater portion of ecosystem functioning than traditional measures of taxon diversity (Díaz and Cabido, 2001; Petchey et al., 2004).

Contrary to taxon diversity, phylogenetic diversity entails the evolutionary relationships amongst taxa (Vellend et al., 2010). When it is difficult to identify or measure those properties that are relevant to the ecosystem function under study, phylogenetic diversity may be a useful proxy for functional diversity since it often encompasses most of the variation in functional traits within a community (Cadotte et al., 2011; Srivastava et al., 2012). The rationale behind this approach is that phylogenetic relatedness usually indicates ecological resemblance, i.e. the more closely related two individuals are, the higher the likelihood that they are functionally similar (but see e.g. Gravel et al., 2012; Srivastava et al., 2012). Cadotte et al. $(2008,2009)$ discovered that phylogenetic diversity was a better predictor of ecosystem functioning than both species and functional group richness. Moreover, not only individuals belonging to different species may differ in functional characteristics, but also considerable intraspecific variability in functional traits is known to occur (Bolnick et al., 2011; Messier et al., 2010). This finding calls for a traitbased instead of a taxon-based approach in examining the effect of diversity on ecosystem functioning.

Deep-sea nematodes are highly diverse (Lambshead and Boucher, 2003), and owing to their omnipresence they can be used to study broad-scale geographic patterns in diversity (Lambshead et al., 2002) as well as the importance of diversity to ecosystem functioning (Danovaro et al., 2008a). Nematodes may influence an important ecosystem function like the bacterial breakdown of organic matter through bioturbation and irrigation (Pike et al., 2001), thereby enhancing nutrient and/or oxygen fluxes (Alkemade et al., 1992; Aller and Aller, 1992), bacterivory (De Mesel et al., 2003) or the provision of optimal growth conditions for bacteria in their mucus trails (Moens et al., 2005; Riemann and Helmke, 2002). Here, we investigated the variation in nematode taxon (genus) and functional diversity along longitudinal (reaching from the Galicia Bank in the Northeast Atlantic to the eastern Mediterranean Basin) and bathymetric (1200-1900-3000 m) gradients within deep-sea sediments. The first aim of this study was to identify potential environmental drivers (i.e. magnitude and variability in seafloor particulate organic carbon (POC) flux and sediment particle size 
diversity) of nematode taxon and functional diversity. Specifically, we explored the form of the diversity-productivity curve (unimodal, positive or negative) by characterising the relationship between nematode diversity and the magnitude of the POC flux to the seabed. Since most of our stations were located within the oligotrophic Mediterranean Sea, we expected to see a positive relation between diversity and seafloor POC flux. Our second aim was to determine how nematode diversity relates to ecosystem functioning. Concretely, we presumed that higher taxon diversity results in higher functional diversity, which in turn stimulates nematode carbon mineralisation. Danovaro et al. (2008a) observed an exponential relationship between nematode species diversity and ecosystem functioning, and so we may expect this type of relation for nematode genus diversity as well if we presume that higher relatedness results in higher functional similarity. The rate of carbon mineralisation by the nematode community was assessed by estimating respiration rates from biomass measurements.

\section{Materials and methods}

\subsection{Study region and sampling strategy}

Sediment samples were collected at 1200, 1900 and $3000 \mathrm{~m}$ water depth along a longitudinal transect spanning the Galicia Bank in the Northeast Atlantic and the Mediterranean Basin (Fig. 1, Table 1). The regions that were sampled were, from west to east, the Galicia Bank region, and the Algerian, Algero-Provençal, Ionian and Levantine basins in the Mediterranean Sea. Samples comprised either subsamples from box cores taken with multicorer cores or actual multicorer samples. We used cores with differing surface areas (see 2.3 and Table 1), but standardised subsamples of maximum 100 nematodes per sediment layer were used for diversity analysis. Sediment cores were sliced horizontally per $\mathrm{cm}$ down to $5 \mathrm{~cm}$, and from 5 to $10 \mathrm{~cm}$ sediment depth. Next, these sediment sections were fixed in seawater-buffered $4 \%$ formalin.

\subsection{Environmental variables}

Grain size data were available for the top $5 \mathrm{~cm}$ of the sediment, and were averaged over the five sediment depth layers. Sediment particle size diversity (SED) was computed as the Shannon-Wiener diversity index based on the percent dry weight of 10 particle size classes (i.e. $<4,4-38,38$ 63, 63-125, 125-250, 250-500, 500-800, 800-1000, 1000$1600,>1600 \mu \mathrm{m})$ (Etter and Grassle, 1992; Leduc et al., 2011). The seasonal variability in surface primary productivity (SVI) was calculated as the coefficient of variation (i.e. standard deviation divided by the mean) of monthly net primary productivity (NPP) values (Lutz et al., 2007), which were extracted from the vertically generalised production model (VGPM; resolution: $1^{\circ}$ ) (Behrenfeld and Falkowski,
1997) and downloaded from http://www.science.oregonstate. edu/ocean.productivity/. We considered SVI as a proxy for the intermittency with which organic matter is deposited at the deep-sea bed (referred to as seasonality or seasonal variability in POC flux in the remainder of the text). The VGPM estimate of NPP values was based on satellite measurements of sea surface temperature (SST), surface water $\mathrm{Chl} a$ concentrations, and photosynthetically active radiation. Estimates of the particulate organic carbon (POC) flux to the seafloor (abbreviated as POC in the remainder of the text) were approximated on the basis of water depth and SVI values following Lutz et al. (2007).

\subsection{Nematode diversity}

The formalin-fixed sediment samples were washed over a $32 \mu \mathrm{m}$ mesh sieve, and the meiofauna were extracted from the sediment by Ludox centrifugation (Heip et al., 1985). Where possible, around 100 nematodes were hand picked from each sediment layer and identified to genus level. Genus abundance data for the top 0 to $10 \mathrm{~cm}$ of each sediment core were obtained by summing genus counts in all sediment slices, taking into account total nematode abundances in each slice. Diversity indices were calculated per core and hence signify point diversity values. Genus diversity was evaluated by means of expected genus richness EG(20), Pielou's evenness $\left(J^{\prime}\right)$, as well as Shannon-Wiener diversity $\left(H^{\prime}, \log _{e}\right)$, which incorporates both the number of genera and their relative abundances. Functional nematode diversity was assessed using the following metrics:

- On the basis of the morphology of the buccal cavity, nematode genera can be appointed to one of the following four feeding types: selective deposit feeder (1A), non-selective deposit feeder (1B), epistrate feeder (2A) and predators/scavengers (2B) (Wieser, 1953). Nematode trophic diversity (TD) was computed as the reciprocal of the trophic diversity index given by Heip et al. (1985):

$$
\mathrm{TD}=\frac{1}{\sum_{i=1}^{4} q_{i}^{2}},
$$

where $q_{i}=$ the relative abundance of feeding type $i$. Consequently, the value of TD varied between 1 (all individuals belong to the same feeding guild) and 4 (all 4 feeding types comprise the same number of individuals). Since all four feeding guilds were represented in all sediment cores studied, TD could be considered as a measure of trophic evenness (Mason et al., 2005).

- Based on their life history strategies, nematode genera can be assigned a c-p (coloniser-persister) score ranging between 1 (colonisers: short generation time, high reproduction rate and colonisation ability and tolerant 


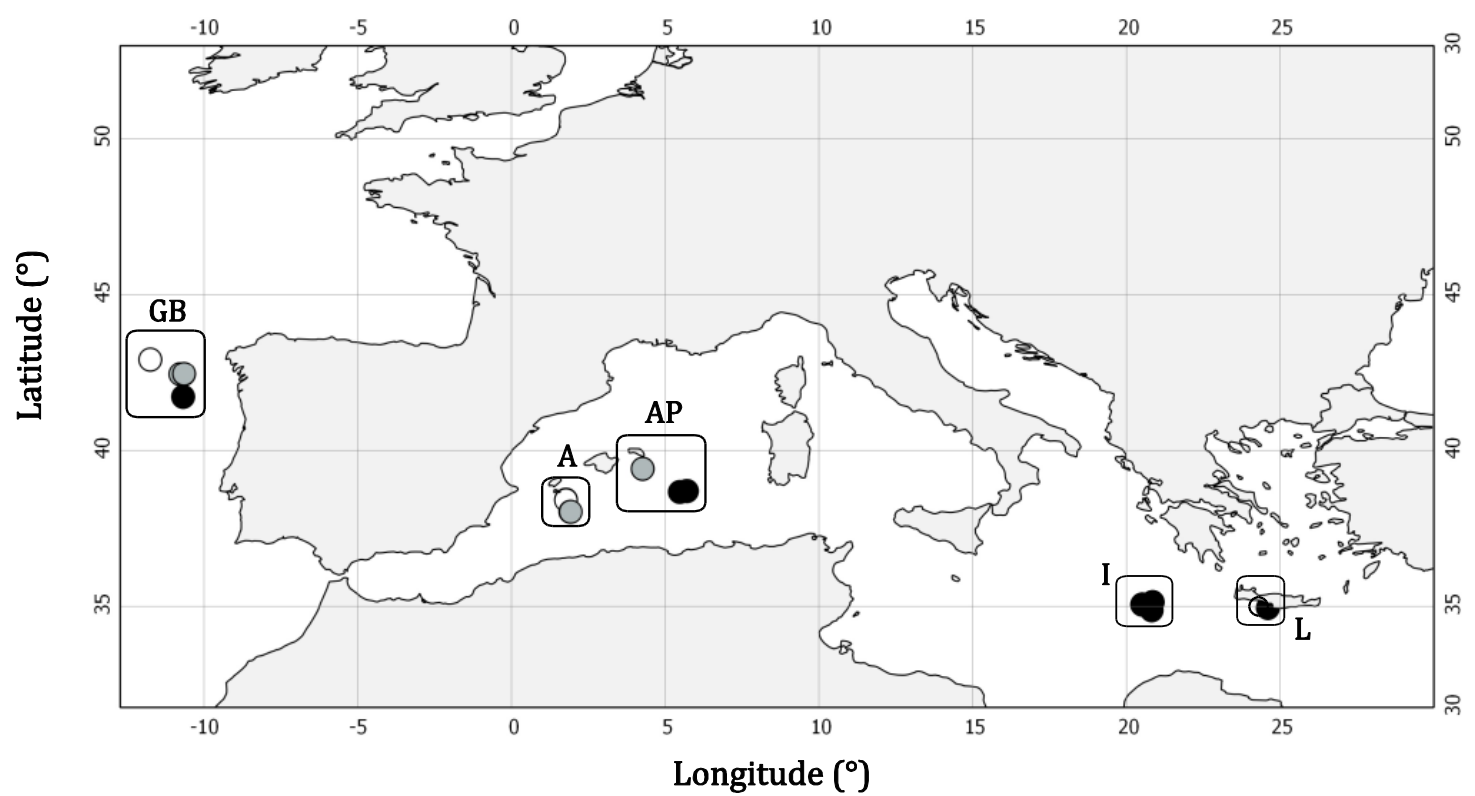

Fig. 1. Map with sampling locations. Colours indicate approximate water depth (white: $1200 \mathrm{~m}$, grey: $1900 \mathrm{~m}$, black: $3000 \mathrm{~m}$ ). The rectangles enclose samples that were collected within the same region (GB: Galicia Bank region, A: Algerian Basin, AP: Algero-Provençal Basin, I: Ionian Basin and L: Levantine Basin).

towards pollution and disturbance) and 5 (persisters: long life cycle, low reproduction potential, sensitive to disturbance and pollution) (Bongers, 1990). Genera with a c-p score of 2, 3 or 4 are intermediate between colonisers and persisters. Monhysterid genera were assigned to the c-p 2 class ("general opportunists") as advised by Bongers et al. (1995), and as such there were no nematodes belonging to $\mathrm{c}-\mathrm{p}$ class 1 ("enrichment opportunists"). We calculated the Shannon-Wiener diversity index based on the partitioning of nematode individuals over the $4 \mathrm{c}-\mathrm{p}$ classes encountered, and termed this $c-p$ diversity.

- As measures for taxonomic or phylogenetic diversity (not to be confused with the "phylogenetic diversity index" PD, which is an example of a phylogenetic diversity index; see Clarke and Warwick, 2001b), we calculated average taxonomic distinctness based on quantitative $\left(\Delta^{*}\right)$ and presence-absence data $\left(\Delta^{+}\right)$(with lower distinctness indicative of a higher average relatedness), as well as the variation in taxonomic distinctness $\left(\Lambda^{+}\right.$, a measure for the imbalance of the taxonomic tree, based on presence-absences) (for formulas see Clarke and Gorley, 2006; Clarke and Warwick, 2001a; Warwick and Clarke, 1998). Assuming that $\Lambda^{+}$indicates functional unevenness, and higher values point to less functionally diverse communities, we used $1 / \Lambda^{+}$to quantify taxonomic or functional evenness. The two average taxonomic distinctness metrics measure functional divergence. Using the ellipse plots in the TAXDEST routine in Primer, we investigated whether $\Delta^{+}$and $\Lambda^{+}$were mechanistically related (Clarke and Warwick, 2001a). We used the following taxonomic levels to calculate the phylogenetic or taxonomic diversity indices: class, subclass, order, suborder, superfamily, family and genus, according to the classification by De Ley et al. (2006), and assumed equal step length.

- Finally, we measured length $(L, \mu \mathrm{m})$ and width $(W$, $\mu \mathrm{m})$ of all nematodes that were mounted on slides for identification purposes to estimate individual wet weight (WW) using Andrassy's (1956) formula, adjusted for the specific gravity of marine nematodes (i.e. $1.13 \mathrm{~g} \mathrm{~cm}^{-3} ; \mu \mathrm{g} \mathrm{WW}=L \times W^{2} / 1500000$ ). Individual biomass $(B)$ in terms of $\mu \mathrm{g}$ ind $^{-1}$ was then calculated as $12.4 \%$ of WW (Jensen, 1984). Next, we calculated biomass diversity (BD) using a ShannonWiener diversity expression adapted for continuous variables according to Quintana et al. (2008). The computation was performed in the Diversity08 software available at http://limnolam.org/.

Taxon (genus) and phylogenetic diversity indices were calculated in Primer v6 (Clarke and Gorley, 2006).

In addition to these diversity indices, we computed the $\mathrm{ma}$ turity index (MI) of a nematode assemblage as the weighted average of the individual genus $\mathrm{c}-\mathrm{p}$ values:

$$
\mathrm{MI}=\sum_{i=1}^{n} v(i) f(i)
$$


Table 1. Sampling details. Indicated are the region where samples were collected in (GB: Galicia Bank region, A: Algerian Basin, AP: Algero-Provençal Basin, I: Ionian Basin and L: Levantine Basin), station code (representing region and approximate water depth), latitude (lat) and longitude (long), range of water depths over replicates, number of replicate samples, surface area of the core, and the research vessel (RV) aboard which samples were taken (SDG: Sarmiento de Gamboa). Lat. and long. are expressed in decimal degrees with negative values indicating west (long.) or south (lat.), and positive values indicating east (long.) or north (lat.). Where rounded coordinates of replicates differed, a range is given.

\begin{tabular}{lllrrrrrr}
\hline Region & Period & Station & Lat. & Long. & $\begin{array}{r}\text { Depth } \\
(\mathrm{m})\end{array}$ & $\begin{array}{r}\text { No. of } \\
\text { replicates }\end{array}$ & $\begin{array}{r}\text { Core area } \\
\left(\mathrm{cm}^{2}\right)\end{array}$ & RV \\
\hline GB & Jun/2008 & GB1200 & 42.9 & -11.8 & $1139-1141$ & 3 & 78.54 & Belgica \\
GB & Oct/2008 & GB1900 & $42.4-42.5$ & -10.7 & $1770-1896$ & 3 & 70.88 & Pelagia \\
GB & Oct/2008 & GB3000 & 41.7 & -10.7 & $3066-3072$ & 3 & 70.88 & Pelagia \\
A & Jun/2009 & A1200 & 38.4 & 1.8 & $1211-1214$ & 3 & 69.40 & SDG \\
A & Jun/2009 & A1900 & 38.0 & 1.9 & 2004,2016 & 2 & 69.40 & SDG \\
AP & Nov/2009 & AP1900 & 39.4 & 4.3 & 1582 & 3 & 56.45 & Pelagia \\
AP & Jun/2009 & AP3000 & 38.7 & $5.5-5.7$ & $2841-2846$ & 3 & 69.40 & SDG \\
I & Jun/2008 & I3000 & $34.9-35.1$ & $20.5-20.8$ & $2770-2807$ & 7 & 10.18 & Urania \\
L & Jun/2008 & L1200 & 35.0 & 24.6 & $1026-1143$ & 3 & 10.18 & Urania \\
L & Jun/2008 & L3000 & 34.9 & 24.5 & 2647 & 1 & 10.18 & Urania \\
\hline
\end{tabular}

where $v(i)=$ the $\mathrm{c}-\mathrm{p}$ value of genus $i$ and $f(i)$ the relative abundance of that genus (Bongers, 1990; Bongers et al., 1991, 1995). Hence, the higher the relative abundance of nematode genera with a high $\mathrm{c}-\mathrm{p}$ score, the higher the value of MI. This functional response measure gives an idea about how stable is the environment in which nematodes live.

\subsection{Nematode respiration}

Individual nematode respiration rates $\left(R ; \mu \mathrm{g} \mathrm{C}\right.$ ind $\left.^{-1} \mathrm{~d}^{-1}\right)$ were calculated on the basis of individual biomass using the formula of Soetaert et al. (1997), which was based on values provided by de Bovée and Labat (1993):

$R=0.0449 \times B^{0} .8554 \times \exp ^{\ln Q_{10} / 10(T-20)}$,

where $Q_{10}=2$, and $T=$ temperature $\left({ }^{\circ} \mathrm{C}\right.$; measured at the seabed at each station). Nematode total respiration rates $\left(\mu \mathrm{g} \mathrm{C} 10 \mathrm{~cm}^{-2} \mathrm{~d}^{-1}\right)$ were computed as the product of $R$ with total nematode biomass $\left(\mu \mathrm{g} \mathrm{C} 10 \mathrm{~cm}^{-2}\right)$. Total nematode biomass $\left(\mu \mathrm{g} \mathrm{C} 10 \mathrm{~cm}^{-2}\right.$ ) was obtained by multiplying for each station the arithmetic mean of $B$ with total density (ind. $10 \mathrm{~cm}^{-2}$ ).

\subsection{Data analysis}

Geographic (longitudinal and bathymetric) and environmental trends (relationship with POC, SVI and SED) in nematode diversity, as well as the relationship between diversity and total respiration were evaluated with (multiple) linear regression. To account for region-specific bathymetric patterns in diversity, we included an interaction term between depth and longitude in our models. This interaction term was, however, never significant. Regressions of total respiration against diversity were run both with (accounting for total biomass) and without total nematode biomass (not accounting for total biomass) as an independent variable to evaluate confounding biomass effects on respiration rates. Relationships amongst taxon and functional diversity indices were explored with Spearman rank correlations, corrected for multiple testing using the method of Benjamini and Yekutieli (2001). Here, we used correlation analysis because we did not assume a relationship of functional dependence between these variables (Zar, 2010). In addition, we checked for correlations between total abundance and all diversity indices.

For the linear regression analysis, partial residual plots were used to examine the linearity of the relationship between the dependent and independent variables (MoyaLaraño and Corcobado, 2008). The other assumptions of linear regression (homogeneity of variances, normally distributed residuals, absence of outliers) were checked visually on the basis of the residual plots (Zuur et al., 2010). Additionally, normality of the residuals and homogeneity of variances were tested using a Shapiro-Wilk test and a non-constant variance score test, respectively. When the variance inflation factors of the independent variables exceeded 5, indicative of multicollinearity, variables were centred (i.e. from each observation the average of the variable was subtracted). When assumptions were not met, independent variables or the dependent variable were $\log _{e}$ transformed or squared. When a unimodal pattern was evident for an independent variable, the quadratic term of this variable was added. The minimal adequate model was selected on the basis of the $P$ values of the partial regression tests. Models with and without quadratic terms were compared with an ANOVA "lack of fit" test. Our samples were clustered per region (Fig. 1) and thus we checked for spatial autocorrelation which can lead to an increased chance of type I errors (i.e. falsely rejecting the null hypothesis) (Dormann et al., 2007). We conducted global Moran's $I$ tests on the residuals of all linear 
regression models (Plant, 2012), which showed no significant spatial autocorrelation. Nevertheless, to account for the dependencies between samples collected in the same region, we fitted a linear mixed-effect (LME) model with region as a random factor and the aforementioned independent variables as fixed effects to our data. When the likelihood ratio (LR) test indicated that the random region effect was not statistically significant (Pinheiro and Bates, 2000), this term was removed and we proceeded with the linear regression model (LM). When the random region effect resulted in a significant improvement of the model (indicating a significant influence of spatial autocorrelation on LM results), however, we interpreted the results of the LME. Adjusted $R^{2}\left(R_{\text {adj }}^{2}\right)$ and marginal $R^{2}\left(R_{\mathrm{m}}^{2}\right.$ : variance explained by the fixed effects; Nakagawa and Schielzeth, 2013) denote the goodness of fit of the linear models and the linear mixed-effect models, respectively.

All statistical analyses were conducted in R (R Core Team, 2012) with the packages car (linear regression assumption checks; Fox and Weisberg, 2011), spdep (test for spatial autocorrelation; Bivand, 2012), psych (correlation analysis with a correction for multiple testing; Revelle, 2012), MuMIn (calculation of $R_{\mathrm{m}}^{2}$; Barton, 2013) and nlme (fit LME models; Pinheiro et al., 2012). Graphs were made with the ggplot2 package (Wickham, 2009). When two independent variables had a significant effect on nematode diversity or respiration in the LM, the isolated effect of each variable was shown using partial regression plots. We added the means of the raw variables to the residuals displayed on the axes to place these on the same scale as the raw variables (Moya-Laraño and Corcobado, 2008).

\section{Results}

\subsection{Longitudinal and bathymetric patterns in nematode diversity}

The results of the regression analyses examining the longitudinal and bathymetric trends in nematode diversity are shown in Table 2. The phylogenetic diversity index $\Delta^{+}$, the diversity of life history strategies (c-p diversity), trophic diversity (TD), the maturity index (MI) and the index of biomass diversity (BD) showed no trend with water depth or longitude. Shannon-Wiener diversity $H^{\prime}$ (Fig. 2a) and expected genus richness EG(20) (Fig. 2b) both declined with water depth, but showed no longitudinal trend. Values of Pielou's evenness $J^{\prime}$ (Fig. 2c), taxonomic distinctness based on quantitative data $\Delta^{*}$ (Fig. 2d) and taxonomic evenness $1 / \Lambda^{+}$(Fig. 2e) increased from west to east, but remained constant with water depth. The ellipse plots constructed with the TAXDEST routine showed that $\Delta^{+}$and $\Lambda^{+}$were not mechanistically related, meaning they were measuring different properties of the taxonomic tree (data not shown).
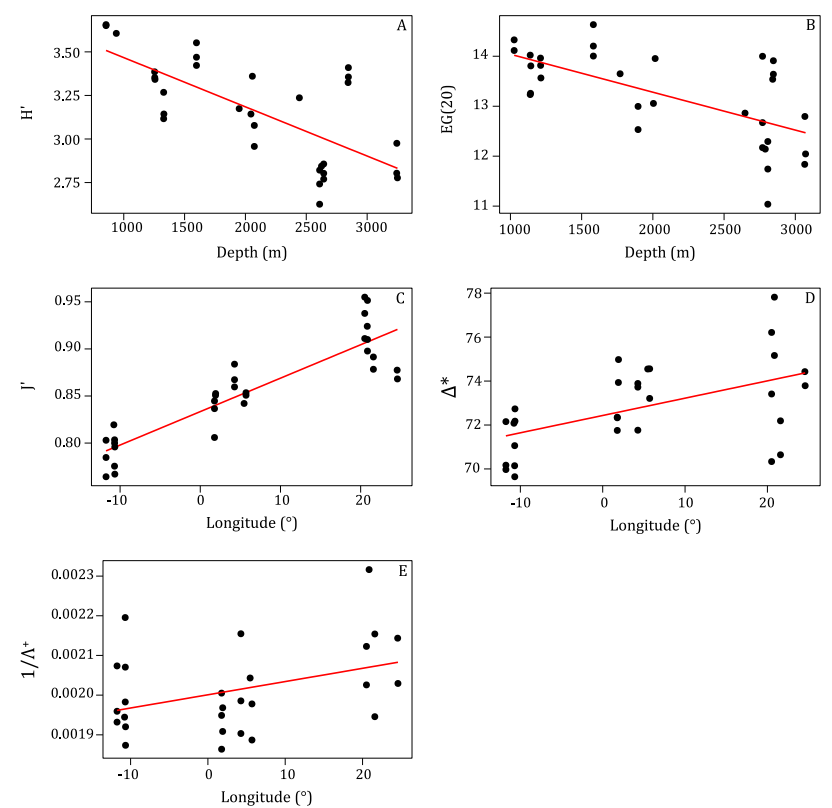

Fig. 2. Bathymetric and longitudinal trends in nematode diversity. For $H^{\prime}$ and $\operatorname{EG}(20)$, partial regression plots were constructed to show the isolated effect of water depth, while the other plots show marginal regressions. $H^{\prime}$ : Shannon-Wiener diversity, EG(20): expected genus richness for a sample of 20 individuals, $J^{\prime}$ : Pielou's evenness, $\Delta^{*}$ : average taxonomic distinctness based on quantitative data, $1 / \Lambda^{+}$: taxonomic evenness. The goodness of fit of these regressions is indicated in Table 2.

\subsection{Environmental drivers of nematode diversity}

Indices $J^{\prime}, \mathrm{c}-\mathrm{p}$ diversity, $1 / \Lambda^{+}$and $\mathrm{BD}$ did not relate to seasonal variability in POC flux (SVI), sediment particle size diversity (SED) or seafloor POC flux (POC). Both $H^{\prime}$ (Fig. 3a) and EG(20) (Fig. 3b) showed a positive linear relationship with $\log _{e}$-transformed POC. TD related inversely with SED (Fig. 3c), whereas taxonomic distinctness based on presence-absence $\left(\Delta^{+}\right.$, Fig. 3g) and quantitative data $\left(\Delta^{*}\right.$, Fig. 3e) increased with increasing SED. MI (Fig. 3d) and $\Delta^{*}$ (Fig. 3h) were influenced negatively by SVI, and $\Delta^{+}$declined with increasing POC values (Fig. 3f).

\subsection{Relationship between nematode taxon and functional diversity}

Pielou's evenness $J^{\prime}$ was the only diversity index that was affected significantly by abundance (Spearman rank, $r=-0.87, P<0.001)$. After correcting for multiple testing, expected genus richness EG(20) correlated positively with c-p diversity (Spearman rank, $r=0.63, P<0.01$; Fig. 4). The other taxon diversity indices did not relate to any of the functional diversity measures. 
Table 2. Results of linear models (LM), the likelihood ratio (LR) test and the linear mixed-effect models (LME) for the regression of water depth and longitude against nematode diversity. For the independent variables depth and longitude (long), the estimated size of the effect and the associated $P$ value are given. For EG(20) both long and long ${ }^{2}$ were retained in the model. For $H^{\prime}$ and BD, long was squared (long ${ }^{2}$ ) to comply with regression assumptions. $H^{\prime}$ : Shannon-Wiener diversity, EG(20): expected genus richness for a sample of 20 individuals, $J^{\prime}$ : Pielou's evenness, TD: trophic diversity, c-p diversity: diversity of $\mathrm{c}-\mathrm{p}$ (life history) classes, MI: maturity index, $\Delta^{+}:$average taxonomic distinctness based on presence-absence data, $\Delta^{*}$ : average taxonomic distinctness based on quantitative data, $1 / \Lambda^{+}:$taxonomic evenness, BD: biomass diversity, $R_{\text {adj }}^{2}$ : adjusted $R^{2}, R_{\mathrm{m}}^{2}$ : marginal $R^{2}$, and G.o.f.: goodness of fit.

\begin{tabular}{|c|c|c|c|c|c|c|c|}
\hline & \multicolumn{3}{|c|}{ LM } & \multirow[t]{2}{*}{ LR test } & \multicolumn{3}{|c|}{ LME } \\
\hline & G.o.f. & Depth & Longitude & & G.o.f. & Depth & Longitude \\
\hline$H^{\prime}$ & $\begin{array}{l}R_{\mathrm{adj}}^{2}=0.72 \\
P<0.001\end{array}$ & $\begin{array}{l}-2.8 \times 10^{-4} \\
P<0.001\end{array}$ & $\begin{array}{l}\text { long }^{2}:-9.4 \times 10^{-4} \\
P<0.001\end{array}$ & $\begin{array}{l}\mathrm{LR}=37.09 \\
P<0.001\end{array}$ & $R_{\mathrm{m}}^{2}=0.44$ & $\begin{array}{l}-1.8 \times 10^{-4} \\
P<0.001\end{array}$ & $\begin{array}{l}\text { long }^{2}:-7.3 \times 10^{-4} \\
P=0.06\end{array}$ \\
\hline$J^{\prime}$ & $\begin{array}{l}R_{\mathrm{adj}}^{2}=0.79 \\
P<0.001\end{array}$ & $\begin{array}{l}- \\
-\end{array}$ & $\begin{array}{l}3.6 \times 10^{-3} \\
P<0.001\end{array}$ & $\begin{array}{l}\mathrm{LR}=9.81 \\
P<0.01\end{array}$ & $R_{\mathrm{m}}^{2}=0.66$ & $\begin{array}{l}- \\
-\end{array}$ & $\begin{array}{l}3.1 \times 10^{-3} \\
P=0.001\end{array}$ \\
\hline $\mathrm{EG}(20)$ & $\begin{array}{l}R_{\mathrm{adj}}^{2}=0.53 \\
P<0.001\end{array}$ & $\begin{array}{l}-7.4 \times 10^{-4} \\
P<0.001\end{array}$ & $\begin{array}{l}\text { long: } 3.5 \times 10^{-2} \text {; } \\
\text { long } 2:-2.8 \times 10^{-3} \\
\text { long: } P=0.01 \\
\text { long } 2: P<0.01\end{array}$ & $\mathrm{LR}=4.34$ & $R_{\mathrm{m}}^{2}=0.43$ & $\begin{array}{l}-6.7 \times 10^{-4} \\
P<0.001\end{array}$ & $\begin{array}{l}\text { long: } 3.6 \times 10^{-2} \text {; } \\
\text { long } 2:-2.7 \times 10^{-3} \\
\text { long: } P=0.25 \text {; } \\
\text { long }^{2}: P=0.13\end{array}$ \\
\hline TD & $\begin{array}{l}R_{\mathrm{adj}}^{2}=0.17 \\
P=0.01\end{array}$ & $\begin{array}{l}- \\
-\end{array}$ & $\begin{array}{l}8.0 \times 10^{-3} \\
P=0.01\end{array}$ & $\begin{array}{l}\mathrm{LR}=5.60 \\
P<0.05\end{array}$ & $R_{\mathrm{m}}^{2}=0.20$ & $\begin{array}{l}- \\
-\end{array}$ & $\begin{array}{l}8.8 \times 10^{-3} \\
P=0.15\end{array}$ \\
\hline $\mathrm{C}-\mathrm{p} \operatorname{div}$ & $\begin{array}{l}R_{\mathrm{adj}}^{2}=0.09 \\
P=0.06\end{array}$ & $\begin{array}{l}-2.6 \times 10^{-5} \\
P=0.06\end{array}$ & $\begin{array}{l}- \\
-\end{array}$ & $\begin{array}{l}\mathrm{LR}=9.62 \\
P<0.01\end{array}$ & $R_{\mathrm{m}}^{2}=0.008$ & $\begin{array}{l}-7.0 \times 10^{-6} \\
P=0.54\end{array}$ & $\begin{array}{l}- \\
-\end{array}$ \\
\hline MI & $\begin{array}{l}R_{\mathrm{adj}}^{2}=0.09 \\
P=0.06\end{array}$ & $\begin{array}{ll}- \\
-\end{array}$ & $\begin{array}{l}3.2 \times 10^{-3} \\
P=0.06\end{array}$ & - & - & $\begin{array}{ll}- \\
-\end{array}$ & $\begin{array}{l}- \\
-\end{array}$ \\
\hline$\Delta^{*}$ & $\begin{array}{l}R_{\mathrm{adj}}^{2}=0.25 \\
P<0.01\end{array}$ & $\begin{array}{l}- \\
-\end{array}$ & $\begin{array}{l}0.1 \\
P<0.01\end{array}$ & $\begin{array}{l}\mathrm{LR}=0.81 \\
P=0.37\end{array}$ & - & - & - \\
\hline$\Delta^{+}$ & $\begin{array}{l}R_{\mathrm{adj}}^{2}=0.08 \\
P=0.07\end{array}$ & $\begin{array}{l}6.6 \times 10^{-4} \\
P=0.07\end{array}$ & $\begin{array}{l}- \\
-\end{array}$ & $\begin{array}{l}- \\
-\end{array}$ & - & $\begin{array}{l}- \\
-\end{array}$ & $\begin{array}{l}- \\
-\end{array}$ \\
\hline $1 / \Lambda^{+}$ & $\begin{array}{l}R_{\mathrm{adj}}^{2}=0.12 \\
P<0.05\end{array}$ & $\begin{array}{l}- \\
-\end{array}$ & $\begin{array}{l}3.3 \times 10^{-6} \\
P<0.05\end{array}$ & $\begin{array}{l}\mathrm{LR}=0.69 \\
P=0.41\end{array}$ & - & $\begin{array}{l}- \\
-\end{array}$ & $\begin{array}{l}- \\
-\end{array}$ \\
\hline $\mathrm{BD}$ & $\begin{array}{l}R_{\mathrm{adj}}^{2}=0.07 \\
P=0.08\end{array}$ & - & $\begin{array}{l}\text { long }^{2}:-2.7 \times 10^{-4} \\
P=0.08\end{array}$ & - & - & - & - \\
\hline
\end{tabular}

\subsection{Effect of diversity on respiration rates in nematode communities}

In the regressions of diversity against total respiration, only indices $H^{\prime}$ and BD had a statistically significant effect (Table 4). $H^{\prime}$ showed a positive linear relation with $\log _{e^{-}}$ transformed total respiration, and squared BD related positively and linearly with total respiration (Fig. 5a and b). After accounting for biomass (by including this variable in the regression against respiration), only taxon diversity indices $H^{\prime}$ and $\mathrm{EG}(20)$ had a positive effect on nematode total respiration (Table 5, Fig. 5c and d).

\section{Discussion}

\subsection{Longitudinal and bathymetric patterns in nematode diversity}

One of the first steps in unravelling the drivers of biodiversity constitutes the description of broad-scale geographical patterns. Nematode genus diversity, measured as ShannonWiener diversity and expected genus richness EG(20), did not change along the longitudinal axis between the Galicia Bank (GB) region, in the Northeast Atlantic, and the eastern Mediterranean. In contrast, similar studies based on nematode species found a significant decrease in diversity between the Northeast Atlantic and the southern Adriatic Sea (Danovaro et al., 2009a) and alongside the longitudinal axis 

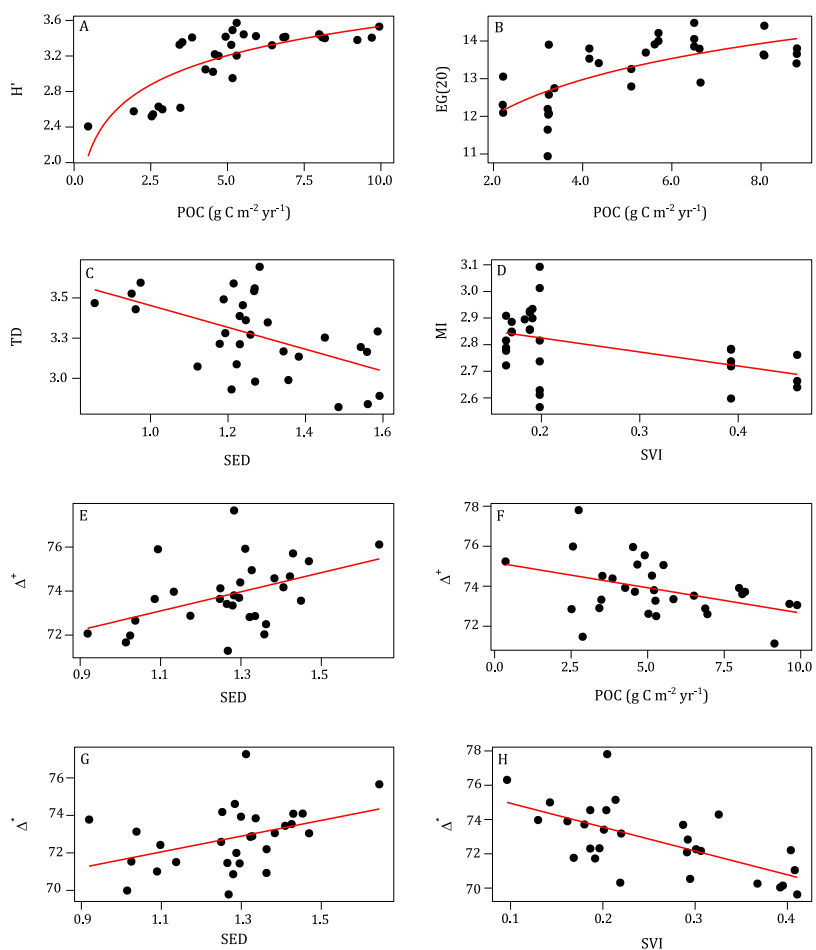

Fig. 3. Environmental drivers of nematode diversity. (A, B, E-H) show partial regression results, whilst (C) and (D) show marginal regressions. POC: seafloor particulate organic carbon flux, SED: sediment particle size diversity, SVI: seasonal variability in POC flux, $H^{\prime}$ : Shannon-Wiener diversity, EG(20): expected genus richness for a sample of 20 individuals, TD: trophic diversity, MI: maturity index, $\Delta^{+}$: average taxonomic distinctness based on presenceabsence data, $\Delta^{*}$ : average taxonomic distinctness based on quantitative data. The goodness of fit of these regressions is shown in Table 3 .

in the Mediterranean Basin (Danovaro et al., 2008b, 2009b, 2010). Even though genus richness remained relatively constant along the longitudinal axis, generic $\left(J^{\prime}\right)$ and taxonomic evenness $\left(1 / \Lambda^{+}\right)$, as well as the average taxonomic distinctness amongst individuals ( $\Delta^{*}$, quantitative data) increased towards the east. Both a higher generic evenness and a greater distance between the more abundant genera in the taxonomic tree can result in higher values of $\Delta^{*}$. Hence, compared to nematode communities in the east, nematode assemblages in the west were characterised by a more imbalanced taxonomic tree (more unequal spread of genera across the taxonomic tree) and a more uneven spread of individuals over the different genera, whether or not in combination with a lower taxonomic distinctness (or higher relatedness) between the dominant genera.

We observed a decline in taxon diversity indices $H^{\prime}$ and EG(20) with increasing water depth, contrasting with numerous previous reports of a unimodal diversity-depth trend for multiple benthic taxa (Menot et al., 2010; Rex and Etter, 2010; Stuart et al., 2003). However, the depth range covered

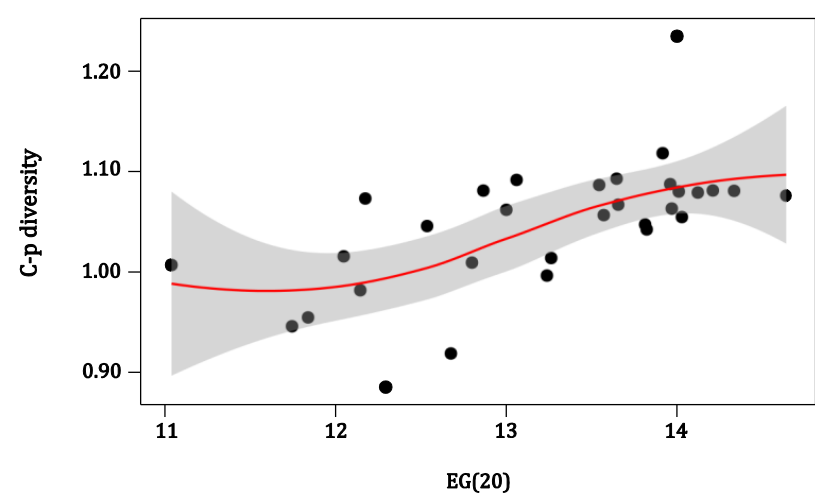

Fig. 4. Significant Spearman rank correlation between taxon diversity (EG(20)) and functional diversity (c-p diversity) of nematodes. The red line and associated grey zone represent a LOESS smoother and the $95 \%$ confidence interval, respectively. EG(20): expected genus richness for a sample of 20 individuals, c-p diversity: diversity of c-p (life history) classes.
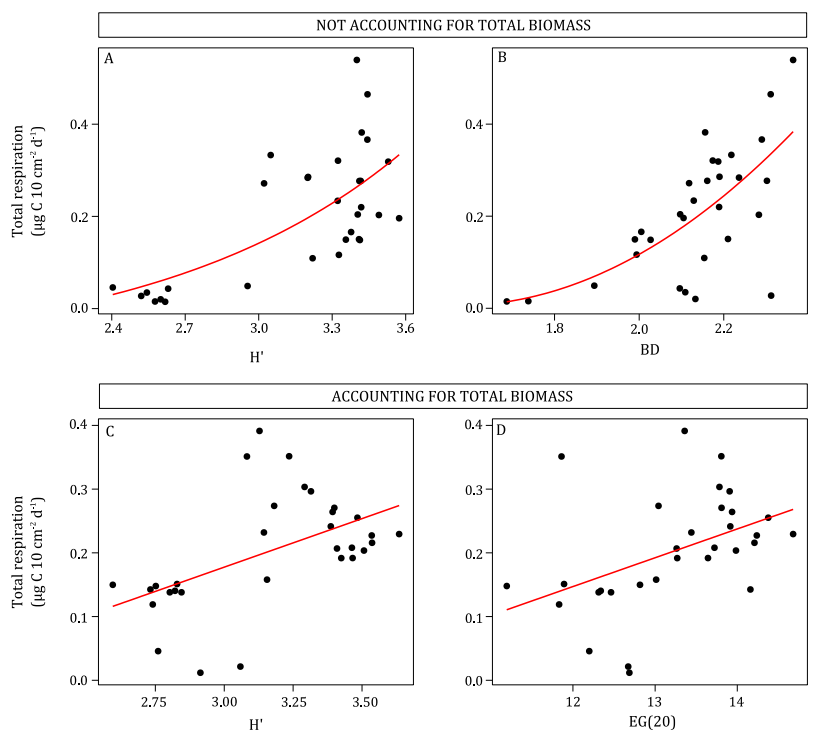

Fig. 5. Relationship between diversity and total respiration in nematode communities. (A) and (B) show the marginal regressions of diversity against respiration (not accounting for total nematode biomass), while (C) and (D) show the partial regressions of diversity against respiration (accounting for total nematode biomass). $H^{\prime}$ : Shannon-Wiener diversity, BD: biomass diversity, EG(20): expected genus richness for a sample of 20 individuals.

here is relatively narrow (1026-3072 m, Table 1) and diversity may be depressed at shallower depths. In other words, it is possible that our samples fell within the descending section of the unimodal bathymetric diversity curve. Danovaro et al. (2010), who considered a larger depth range than us, discovered a hump-shaped bathymetric trend in nematode species diversity, albeit only in the eastern Mediterranean Basin. In contrast, Tselepides et al. (2000) described 
Table 3. Results of linear models (LM), the likelihood ratio (LR) test and linear mixed-effect models (LME) for the regression of sediment particle size diversity (SED), seafloor particulate organic carbon flux (POC) and seasonal variability in POC flux (SVI) against nematode diversity. The estimated size of the effect and the associated $P$ value are given per independent variable. For the regressions against $H^{\prime}, J^{\prime}$, $\mathrm{EG}(20)$ and $\mathrm{c}-\mathrm{p}$ diversity (c-p div), POC was $\log _{e}$ transformed to comply with the assumptions of linear regression. For $\mathrm{c}-\mathrm{p}$ diversity, also SVI was $\log _{e}$ transformed to comply with assumptions. $H^{\prime}$ : Shannon-Wiener diversity, EG(20): expected genus richness for a sample of 20 individuals, $J^{\prime}$ : Pielou's evenness, TD: trophic diversity, c-p diversity: diversity of c-p (life history) classes, MI: maturity index, $\Delta^{+}:$average taxonomic distinctness based on presence-absence data, $\Delta^{*}$ : average taxonomic distinctness based on quantitative data, $1 / \Lambda^{+}:$taxonomic evenness, BD: biomass diversity, $R_{\text {adj }}^{2}$ : adjusted $R^{2}, R_{\mathrm{m}}^{2}$ : marginal $R^{2}$, and G.o.f.: goodness of fit.

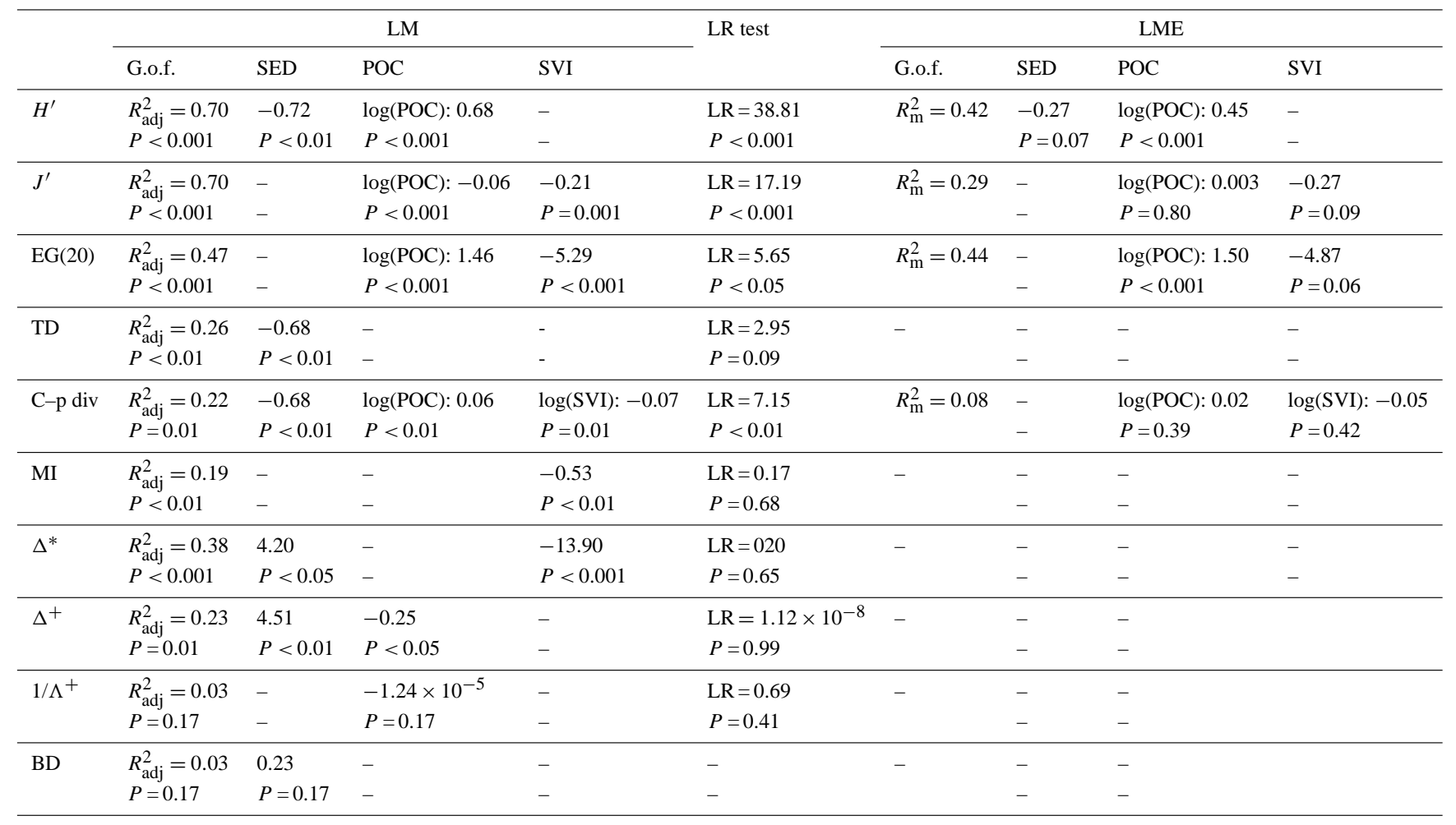

a decrease in macrofaunal diversity between 40 and $1570 \mathrm{~m}$ water depth along the Cretan continental margin. Rex and Etter (2010) speculated that when nutrient loadings become very scarce, as is the case in the Mediterranean, there is a shift from a fully unimodal diversity-depth curve towards just the ascending portion (i.e. positive association between productivity and diversity). Alternatively, the absence of a peak in diversity at intermediate water depths may be related to the unusually warm $\left(13^{\circ} \mathrm{C}\right)$ and isothermal water column in the Mediterranean (Tyler, 2003). Unimodal diversitydepth trends are generally found in open oceans like the Atlantic and the Pacific where temperature decreases rapidly (to barely a few degrees) with depth. As opposed to Danovaro et al. (2009a) and Danovaro et al. (2010), bathymetric diversity patterns did not vary between the different regions that were sampled.

The divergence between the present results and those of Danovaro et al. (2008b) and Danovaro et al. (2010) regarding bathymetric and longitudinal trends in nematode diversity may be attributed to the different taxonomic levels (genera and species, respectively) and sediment depth strata that were investigated $(0-10$ and $0-1 \mathrm{~cm}$, respectively). For deep-sea nematodes inhabiting the Kenyan continental margin, spatial patterns in genus diversity differed substantially from species diversity trends (Muthumbi et al., 2011). In contrast, Leduc et al. (2012b) found very comparable environmental trends in species and genus diversity at the continental slope of New Zealand. The difference in species and genus patterns along the Kenyan margin (Muthumbi et al., 2011) were attributed to the unequal distribution of the number of species per genus, with some genera consisting of many species (e.g. Acantholaimus, De Mesel et al., 2006) and many genera consisting of a few species.

\subsection{Environmental drivers of nematode diversity}

Productivity and its mediation of biological interactions has been proposed as a potential mechanism for the commonly observed unimodal bathymetric and linear latitudinal diversity gradients in deep-sea sediments (Levin et al., 2001; Stuart et al., 2003). Here, the magnitude of seafloor POC flux 
Table 4. Results of linear models (LM), the likelihood ratio (LR) test and linear mixed-effect models (LME) for the regression of nematode diversity against total respiration. The estimated average size of the effect and the associated $P$ value are given per diversity index. For $H^{\prime}$ and $\mathrm{EG}(20)$, respiration (resp) was $\log _{e}$ transformed to comply with the assumptions of linear regression. $J^{\prime}$ and $\mathrm{BD}$ were $\log _{e}$ transformed and squared, respectively, to comply with assumptions. $H^{\prime}$ : Shannon-Wiener diversity, EG(20): expected genus richness for a sample of 20 individuals, $J^{\prime}$ : Pielou's evenness, TD: trophic diversity, c-p diversity: diversity of c-p (life history) classes, MI: maturity index, $\Delta^{+}:$average taxonomic distinctness based on presence-absence data, $\Delta^{*}$ : average taxonomic distinctness based on quantitative data, $1 / \Lambda^{+}:$taxonomic evenness, BD: biomass diversity, $R_{\text {adj }}^{2}$ : adjusted $R^{2}, R_{\mathrm{m}}^{2}$ : marginal $R^{2}$, and G.o.f.: goodness of fit.

\begin{tabular}{|c|c|c|c|c|c|}
\hline & \multicolumn{2}{|r|}{ LM } & \multirow[t]{2}{*}{ LR test } & \multicolumn{2}{|c|}{ LME } \\
\hline & G.o.f. & Effect of diversity & & G.o.f. & Effect of diversity \\
\hline$H^{\prime}$ & $\begin{array}{l}R_{\mathrm{adj}}^{2}=0.71 \\
P<0.001\end{array}$ & $\begin{array}{l}\log (\text { resp): } 2.45 \\
P<0.001\end{array}$ & $\begin{array}{l}\mathrm{LR}=4.25 \\
P<0.05\end{array}$ & $R_{\mathrm{m}}^{2}=0.51$ & $\begin{array}{l}1.80 \\
P<0.001\end{array}$ \\
\hline$J^{\prime}$ & $\begin{array}{l}R_{\mathrm{adj}}^{2}=0.35 \\
P<0.001\end{array}$ & $\begin{array}{l}\log \left(J^{\prime}\right):-1.35 \\
P<0.001\end{array}$ & $\begin{array}{l}\mathrm{LR}=6.99 \\
P<0.01\end{array}$ & $R_{\mathrm{m}}^{2}=0.02$ & $\begin{array}{l}-0.99 \\
P=0.09\end{array}$ \\
\hline EG(20) & $\begin{array}{l}R_{\mathrm{adj}}^{2}=0.24 \\
P<0.01\end{array}$ & $\begin{array}{l}\log (\text { resp }):-9.85 \\
P<0.01\end{array}$ & $\begin{array}{l}\mathrm{LR}=26.43 \\
P<0.001\end{array}$ & $R_{\mathrm{m}}^{2}=0.02$ & $\begin{array}{l}\log (\text { resp): } 0.17 \\
P=0.23\end{array}$ \\
\hline TD & $\begin{array}{l}R_{\mathrm{adj}}^{2}=0.00 \\
P=0.37\end{array}$ & $\begin{array}{l}-0.10 \\
P=0.37\end{array}$ & $\begin{array}{l}- \\
-\end{array}$ & - & $\begin{array}{l}- \\
-\end{array}$ \\
\hline $\mathrm{C}-\mathrm{p}$ div & $\begin{array}{l}R_{\mathrm{adj}}^{2}=0.10 \\
P=0.05\end{array}$ & $\begin{array}{l}0.88 \\
P=0.05\end{array}$ & $\begin{array}{l}\mathrm{LR}=11.10 \\
P<0.001\end{array}$ & $R_{\mathrm{m}}^{2}=0.0008$ & $\begin{array}{l}0.08 \\
P=0.87\end{array}$ \\
\hline MI & $\begin{array}{l}R_{\mathrm{adj}}^{2}=0.00 \\
P=0.70\end{array}$ & $\begin{array}{l}-0.08 \\
P=0.70\end{array}$ & $\begin{array}{l}- \\
- \\
-\end{array}$ & - & $\begin{array}{l}- \\
-\end{array}$ \\
\hline$\Delta^{*}$ & $\begin{array}{l}R_{\mathrm{adj}}^{2}=0.00 \\
P=0.56\end{array}$ & $\begin{array}{l}0.005 \\
P=0.56\end{array}$ & $\begin{array}{l}- \\
-\end{array}$ & - & $\begin{array}{l}- \\
-\end{array}$ \\
\hline$\Delta^{+}$ & $\begin{array}{l}R_{\mathrm{adj}}^{2}=0.02 \\
P=0.23\end{array}$ & $\begin{array}{l}0.01 \\
P=0.23\end{array}$ & $\begin{array}{l}- \\
-\end{array}$ & - & $\begin{array}{l}- \\
-\end{array}$ \\
\hline $1 / \Lambda^{+}$ & $\begin{array}{l}R_{\mathrm{adj}}^{2}=0.00 \\
P=0.37\end{array}$ & $\begin{array}{l}-52.08 \\
P=0.37\end{array}$ & $\begin{array}{l}- \\
-\end{array}$ & - & $\begin{array}{l}- \\
-\end{array}$ \\
\hline $\mathrm{BD}$ & $\begin{array}{l}R_{\mathrm{adj}}^{2}=0.40 \\
P<0.001\end{array}$ & $\begin{array}{l}\mathrm{BD}^{2}: 0.14 \\
P<0.001\end{array}$ & $\begin{array}{l}\mathrm{LR}=8.21 \\
P<0.01\end{array}$ & $R_{\mathrm{m}}^{2}=0.18$ & $\begin{array}{l}0.09 \\
P<0.01\end{array}$ \\
\hline
\end{tabular}

had a positive impact on nematode taxon diversity, measured as $H^{\prime}$ and $\mathrm{EG}(20)$, consistent with earlier work on polychaetes (Glover et al., 2002) and nematodes (Lambshead et al., 2002) from the abyssal central Pacific. It was shown that seafloor POC flux declines from the Northeast Atlantic to the eastern Mediterranean (not considering seamount station GB1200) and with water depth (Pape et al., 2013), and hence this environmental factor may partly explain the observed bathymetric decline in taxon diversity (see Sect. 4.1). The detection of a positive association between diversity and productivity does not necessarily negate the existence of a hump-shaped productivity-diversity curve. The productivity gradient considered in this study may occupy only the left, ascending limb of the unimodal diversity-productivity curve (Levin et al., 2001). In support of this, in the Atlantic and the Gulf of Mexico, Menot et al. (2010) found a diversity peak at an organic carbon flux of $10-15 \mathrm{~g} \mathrm{C} \mathrm{m}^{-2} \mathrm{yr}^{-1}$ for several macrofaunal phyla, which is the maximum value of seafloor POC flux observed in our study area. As opposed to the traditionally employed diversity measures (i.e. Shannon-Wiener diversity and expected genus richness), average taxonomic distinctness (based on presence-absence data, $\Delta^{+}$) was inversely related to seafloor POC flux. Hence, along our transect, areas characterised by higher POC input harboured a higher number of relatively closely related genera, whereas areas receiving less POC were inhabited by less, but more distantly related genera. It seems that a high POC flux regime is favouring a higher number of nematode genera that are relatively closely related and consequently exhibit similar properties that allow them to outcompete other genera or withstand predation pressure by larger fauna.

In the present study, higher seasonality in surface productivity (SVI) was reflected in a reduced nematode maturity index, governed by the increased contribution of colonisers or 
Table 5. Results of linear models (LM), and the likelihood ratio (LR) test for the regression of nematode diversity and total nematode biomass against total respiration. Since the LR test was never significant, only the LM results were interpreted. The estimated average size of the effect and the associated $P$ value are given for biomass and each diversity index. Except for the regressions with $H^{\prime}$ and EG(20), biomass (bio) was $\log _{e}$ transformed to comply with the assumptions of linear regression. $H^{\prime}$ : Shannon-Wiener diversity, EG(20): expected genus richness for a sample of 20 individuals, $J^{\prime}$ : Pielou's evenness, TD: trophic diversity, c-p diversity: diversity of c-p (life history) classes, MI: maturity index, $\Delta^{+}$: average taxonomic distinctness based on presence-absence data, $\Delta^{*}$ : average taxonomic distinctness based on quantitative data, $1 / \Lambda^{+}$: taxonomic evenness, BD: biomass diversity, $R_{\text {adj }}^{2}$ : adjusted $R^{2}, R_{\mathrm{m}}^{2}$ : marginal $R^{2}$, and G.o.f.: goodness of fit.

\begin{tabular}{|c|c|c|c|c|}
\hline & \multicolumn{3}{|c|}{ LM } & \multirow[t]{2}{*}{ LR test } \\
\hline & G.o.f. & Effect of biomass & Effect of diversity & \\
\hline \multirow[t]{2}{*}{$H^{\prime}$} & $R_{\mathrm{adj}}^{2}=0.66$ & 0.02 & 0.15 & $\mathrm{LR}=3.56$ \\
\hline & $P<0.001$ & $P<0.001$ & $P<0.01$ & $P=0.06$ \\
\hline \multirow[t]{2}{*}{$J^{\prime}$} & $R_{\mathrm{adj}}^{2}=0.69$ & $\log ($ bio $): 0.12$ & 0.57 & - \\
\hline & $P<0.001$ & $P<0.001$ & $P=0.23$ & - \\
\hline \multirow[t]{2}{*}{$\mathrm{EG}(20)$} & $R_{\mathrm{adj}}^{2}=0.63$ & 0.02 & 0.05 & $\mathrm{LR}=2.85$ \\
\hline & $P<0.001$ & $P<0.001$ & $P=0.01$ & $P=0.09$ \\
\hline \multirow[t]{2}{*}{ TD } & $R_{\mathrm{adj}}^{2}=0.68$ & $\log ($ bio): 0.10 & -0.03 & - \\
\hline & $P<0.001$ & $P<0.001$ & $P=0.65$ & - \\
\hline \multirow[t]{2}{*}{$\mathrm{C}-\mathrm{p}$ div } & $R_{\mathrm{adj}}^{2}=0.68$ & $\log ($ bio $): 0.10$ & -0.007 & - \\
\hline & $P<0.001$ & $P<0.001$ & $P=0.98$ & - \\
\hline \multirow[t]{2}{*}{ MI } & $R_{\mathrm{adj}}^{2}=0.67$ & $\log$ (bio): 0.10 & $-18.3 \times 10^{-4}$ & - \\
\hline & $P<0.001$ & $P<0.001$ & $P=0.99$ & - \\
\hline \multirow[t]{2}{*}{$\Delta^{*}$} & $R_{\mathrm{adj}}^{2}=0.68$ & $\log$ (bio): 0.10 & -0.003 & - \\
\hline & $P<0.001$ & $P<0.001$ & $P=0.50$ & - \\
\hline \multirow[t]{2}{*}{$\Delta^{+}$} & $R_{\mathrm{adj}}^{2}=0.68$ & $\log$ (bio): 0.10 & -0.005 & - \\
\hline & $P<0.001$ & $P<0.001$ & $P=0.45$ & - \\
\hline \multirow[t]{2}{*}{$1 / \Lambda^{+}$} & $R_{\mathrm{adj}}^{2}=0.68$ & $\log ($ bio $): 0.10$ & 13.12 & - \\
\hline & $P<0.001$ & $P<0.001$ & $P=0.70$ & - \\
\hline \multirow[t]{2}{*}{ BD } & $R_{\mathrm{adj}}^{2}=0.68$ & $\log$ (bio): 0.09 & 0.09 & - \\
\hline & $P<0.001$ & $P<0.001$ & $P=0.36$ & - \\
\hline
\end{tabular}

opportunists to nematode standing stock (Bongers and Ferris, 1999; Bongers et al., 1991). It is believed that these nematodes can cope better with variable environmental conditions such as those induced by pulsed organic matter input. Nematode communities in more seasonal regions displayed also lower average taxonomic distinctness (based on quantitative data, $\left.\Delta^{*}\right)$. This finding suggests that the ability to maintain high abundances under a more pulsed organic matter loading may be confined to certain taxonomic groups. Clearly, our results imply that both the magnitude and the seasonality of seafloor POC flux impact the average taxonomic distinctness within nematode communities, which may be translated to a greater functional distinctness. However, since taxonomic distinctness may be governed by a variety of factors, such as biogeography, environmental factors, habitat characteristics, and stress (Bevilacqua et al., 2012; Leira et al., 2009; Mouillot et al., 2005; Warwick and Clarke, 1995, 1998; Xu et al., 2011), more research into life history strategies, niche requirements and taxon interactions are needed to fully understand the patterns observed here.

Unlike Leduc et al. (2011) (nematode species and genera) and Etter and Grassle (1992) (macrofaunal species), we did not detect an effect of sediment heterogeneity (SED) on nematode genus diversity. We did, however, observe that more heterogeneous sediments harboured nematode assemblages with a higher taxonomic breadth, and possibly a higher functional divergence. The higher habitat heterogeneity may favour the co-existence of more taxonomically dissimilar taxa, with their distinct specific niche requirements. Possibly, the high genus diversity observed by Leduc et al. (2011) coincided with high taxonomic distinctness. Leduc et al. (2011) found no effect of SED on nematode trophic diversity (TD), whereas we uncovered an inverse relationship between SED and TD. It should be stressed that the trends described here 
do not imply causal relationships, and that the decrease in nematode trophic diversity with increasing SED may be driven by a confounding, unmeasured environmental factor (e.g. standing stock of mega or macrofauna). The differential calculation of sediment heterogeneity hampers the comparison between our study and that of Leduc et al. (2011). Whereas we considered ten different grain size classes (see Sect. 2.2), Leduc et al. (2011) used only five sediment grain size classes in their calculation of SED without subdividing the mud fraction $(<63 \mu \mathrm{m})$ of the sediment. Finally, note that our SED calculation and that of Etter and Grassle (1992) and Leduc et al. (2011) was based on dry-sieved sediment fractions and it is possible that this measure of particle diversity is not representative for the in situ size distribution of aggregated sediment particles (Levin et al., 2001; Snelgrove and Butman, 1994).

\subsection{Link between nematode taxon and functional diversity}

Our results showed that nematode communities with higher taxon diversity were characterised by a greater variety of life history strategies (higher $\mathrm{c}-\mathrm{p}$ diversity). If higher $\mathrm{c}-\mathrm{p}$ diversity governs enhanced resistance against environmental fluctuations or resilience following disturbance, this may point to a positive long-term effect of taxon diversity on ecosystem functioning (Loreau, 2000). We found no links between the other taxon and functional diversity measures, and hence the presence of a relationship between taxon and functional diversity depended on the type of functional traits considered. However, the functional diversity indices computed here might not encompass the entire array of functions performed by the nematode community. For instance, the feeding type classification scheme based on buccal morphology (Wieser, 1953) may be too coarse to represent a truthful proxy for resource partitioning. In support, De Mesel et al. (2003) observed that coastal nematode species belonging to the same feeding guild had a differential influence on cordgrass decomposition rates. The validity of our results concerning the association between taxon and functional diversity in other oceanographic regions remains to be tested as it is partly determined by the degree of redundancy and singularity within a community, as well as by biogeography and biotic interactions (Hooper et al., 2002; Naeem and Wright, 2003).

\subsection{Effect of diversity on respiration rates in nematode communities}

The present study showed that deep-sea nematode communities with higher Shannon-Wiener genus diversity $\left(H^{\prime}\right)$ or higher individual biomass diversity (BD) showed higher total respiration rates, and that the influence of both diversity indices was more pronounced at higher values (as inferred from the exponential and power function describing the de- pendency of respiration on $H^{\prime}$ and $\mathrm{BD}$, respectively). However, when differences in total nematode biomass between samples were accounted for, we only observed a positive linear relationship between taxon diversity (measured as $H^{\prime}$ and expected genus richness $\mathrm{EG}(20)$ ) and total respiration. In other words, nematode communities with the same standing stock showed different respiration rates when genus diversity, but not biomass diversity, differed. Hence, the positive impact of BD on respiration could be attributed to the positive covariance between total biomass and the diversity in individual biomass.

More diverse nematode assemblages may mineralise more carbon when the co-existence of more genera results in a more complete utilisation of all different carbon sources. Consequently, the linear form of the relation between expected genus richness and total respiration may indicate that all genera contributed more or less equally to the decomposition and mineralisation of organic matter, which is in line with the rivet hypothesis (Lawton, 1994; Naeem et al., 1995). Contrary to expectations, we found no proof for functional diversity as a mechanistic link between taxon diversity and ecosystem functioning since none of the functional diversity indices (including taxonomic or phylogenetic diversity) related to both genus diversity and total respiration. Several points can be raised to explain the lack of a significant association between the functional diversity indices and ecosystem functioning. First of all, as mentioned in section 4.3, the metrics computed here may not adequately represent true functional diversity. The diversity in diet composition amongst nematode genera may not be captured by the trophic diversity index. Secondly, the functional diversity measures used here are perhaps not important for the ecosystem function under study, but they may well be for other functions performed by nematodes. For instance, a nematode community which comprises a wide variety of differently sized individuals (high BD) may create more diversified micro-burrow networks within the sediment. This type of cryptobioturbation and bioirrigation may in turn stimulate small-scale yet important biogeochemical processes (Aller and Aller, 1992; Pike et al., 2001), resulting in elevated carbon mineralisation by the entire benthic community. A more relevant measure of functional diversity to nematode carbon mineralisation may be the diversity in digestive systems, mirrored in taxon diversity. Thirdly, it is possible that environmental conditions influencing both functional diversity and respiration rates vary among sites, resulting in an absence of an across-site pattern even when significant biodiversity effects exist within each locale (Cardinale et al., 2000; Hiddink et al., 2009; Loreau, 2000). A fourth point is that total nematode respiration was here estimated on the basis of total nematode biomass and temperature (de Bovée and Labat, 1993) and may not truthfully reflect in situ respiration by the nematode community. Environmental factors other than temperature (Braeckman et al., 2013) and biotic interactions (De Mesel et al., 2006) may influence nematode carbon processing rates. Sounder results 
would have been obtained from the direct measurement of oxygen consumption or carbon dioxide production by nematode communities in deep-sea sediments.

Phylogenetic diversity may serve as a proxy for functional diversity when related taxa are functionally similar (Cadotte et al., 2008, 2009). The present study did not demonstrate a significant effect of phylogenetic diversity on total respiration for deep-sea nematodes. The lack of a relation between phylogenetic diversity and ecosystem functioning may be because (1) functionally important traits do not have a strong phylogenetic signal (or in other words, closely related taxa do not have similar functional trait values), (2) the signal is reduced because of community assembly, or (3) traits that determine dominance are not important for the function under study (Srivastava et al., 2012). The fact that we found no link between taxon and phylogenetic diversity, whereas total respiration was affected positively by taxon diversity, implies that the phylogenetic diversity indices used here do not serve as good surrogates for the diversity of traits important for total respiration (such as feeding behaviour and/or the digestive apparatus).

The different form of the biodiversity-function curve in the present study (linear) and that of Danovaro et al. (2008a) (exponential) may be related to the differences in measures of ecosystem function (nematode respiration rates vs prokaryote biomass and production, bacterial organic matter decomposition and total faunal biomass, respectively), the taxonomic level considered (genera vs. species, respectively), and the sediment depth interval investigated $(0-10 \mathrm{~cm}$ vs $0-1 \mathrm{~cm}$, respectively). As demonstrated for shallow marine and terrestrial systems, different ecosystem processes or properties can respond very dissimilarly to changes in biodiversity (Bolam et al., 2002; Naeem et al., 1995).

We assumed that respiration is dependent on diversity in nematode communities. However, significant regressions do not necessarily imply causation. If both diversity and respiration are influenced by the same environmental factor(s), this would also result in a significant relationship. Temperature promotes respiration rates and, at least for ophiuroids (O'Hara and Tittensor, 2010) and mollusks (Tittensor et al., 2011), also biodiversity. Along our transect, higher POC deposition (food availability) resulted in higher standing stock (Pape et al., 2013) and thus higher respiration rates, but also allowed for more taxa to attain viable population sizes. However, the fact that communities with equal biomass (suggesting equal food availability) with differing diversity showed differing respiration rates indicates that food availability is not the sole factor governing the significant diversityfunction relation. Experimental studies, employing in situ respiration as an ecosystem function, are needed to verify and elucidate the mechanism(s) behind the observed diversityfunction relation.
Since climate change is already affecting the pattern of POC flux to the deep-sea bottom and will continue to do so (Smith et al., 2008), the links between the magnitude and variability in POC flux and taxon diversity, on the one hand, and between taxon diversity and ecosystem functioning, on the other hand, suggests that this global phenomenon will modify, or already is modifying, the functioning of deep-sea ecosystems.

\section{Conclusions}

Several of the nematode diversity indices that we calculated displayed significant bathymetric and longitudinal patterns, which may be partly ascribed to variations in the rate and seasonality of organic matter deposition as well as in sediment heterogeneity. Accounting for confounding biomass effects, we observed a positive linear relationship between nematode taxon diversity and nematode carbon mineralisation, estimated from total nematode biomass. The fact that none of the indices of functional diversity, including phylogenetic diversity, related to both taxon diversity and mineralisation rates suggests that these indices did not encompass the entire array of nematode functional traits that are of importance to nematode carbon mineralisation. Our results suggest potential effects of climate change on nematode carbon mineralisation rates in the deep sea. In light of the progressive change in global climatic patterns, it is clear that we urgently need to improve our knowledge regarding the functions that nematodes perform within deep-sea sedimentary ecosystems and how these are affected by evolutionary processes.

Acknowledgements. This research received funding through the ESF-EuroDEEP BIOFUN project (FWO project number 3G067007) and the European Commission's Seventh Framework Programme HERMIONE project (grant number 226354), as well as through the FWO project G083512W. We are indebted to the crew and scientific personnel during expeditions aboard the RV Belgica (Belgica cruise 2008/13b), RV Pelagia (cruises 64PE295-296 and 64PE314), RV Urania (BIOFUN cruise 2008) and Sarmiento de Gamboa (BIOFUN 2009 Trans-Mediterranean cruise). Bart Beuselinck and Niels Viaene are thanked for grain size analyses. We appreciated the help of Niels Viaene in measuring nematode biovolume and extracting meiofauna, and that of Annick Van Kenhove and Guy De Smet in preparing slides for nematode identification. Last but not least, the authors greatly appreciated the statistical advice provided by Professor Carl Van Gestel, and the help with the interpretation of the taxonomic distinctness indices by Professor Bob Clarke.

Edited by: R. Danovaro 


\section{References}

Alkemade, R., Wielemaker, A., De Jong, S., and Sandee, A. J. J.: Experimental evidence for the role of bioturbation by the marine nematode Diplolaimella dievengatensis in stimulating the mineralization of Spartina anglica detritus, Mar. Ecol.-Prog. Ser., 90, 149-155, 1992.

Aller, R. C. and Aller, J. Y.: Meiofauna and solute transport in marine muds, Limnol. Oceanogr., 37, 1018-1033, 1992.

Andrassy, I.: The determination of volume and weight of nematodes, Acta Zool. Acad. Sci. H., 2, 1-15, 1956.

Balvanera, P., Pfisterer, A. B., Buchmann, N., He, J.-S., Nakashizuka, T., Raffaelli, D., and Schmid, B.: Quantifying the evidence for biodiversity effects on ecosystem functioning and services, Ecol. Lett., 9, 1146-1156, 2006.

Barton, K.: MuMIn: Multi-model inference, $\mathrm{R}$ package version 1.9.0., 2013.

Behrenfeld, M. J. and Falkowski, P. G.: Photosynthetic rates derived from satellite-based chlorophyll concentration, Limnol. Oceanogr., 42, 1-20, 1997.

Bengtsson, J., Engelhardt, K., Giller, P., Hobbie, S., and Lawrence, D.: Slippin' and slidin' between the scales: the scaling components of biodiversity-ecosystem functioning relations, in: Biodiversity and Ecosystem Functioning: Synthesis and Perspectives, vol. 18, edited by: Loreau, M. and Naeem, S., 209-220, Oxford University Press, 2002.

Benjamini, Y. and Yekutieli, D.: The control of the false discovery rate in multiple testing under dependency, Ann. Stat., 29, 11651188, 2001.

Bevilacqua, S., Sandulli, R., Plicanti, A., and Terlizzi, A.: Taxonomic distinctness in Mediterranean marine nematodes and its relevance for environmental impact assessment, Mar. Pollut. Bull., 64, 1409-1416, 2012.

Bivand, R.: spdep: Spatial dependence: weighting schemes, statistics and models, R package version 0.5-53, 2012.

Bolam, S. G., Fernandes, T. F., and Huxham, M.: Diversity, biomass, and ecosystem processes in the marine benthos, Ecol. Monogr., 72, 599-615, 2002.

Bolnick, D. I., Amarasekare, P., Araújo, M. S., Bürger, R., Levine, J. M., Novak, M., Rudolf, V. H. W., Schreiber, S. J., Urban, M. C., and Vasseur, D. A.: Why intraspecific trait variation matters in community ecology, Trends Ecol. Evol., 26, 183-192, 2011.

Bongers, T.: The maturity index: an ecological measure of environmental disturbance based on nematode species composition, Oecologia, 83, 14-19, 1990.

Bongers, T. and Ferris, H.: Nematode community structure as a bioindicator in environmental monitoring, Trends Ecol. Evol., 14, 224-228, 1999.

Bongers, T., Alkemade, R., and Yeates, G.: Interpretation of disturbance-induced maturity decrease in marine nematode assemblages by means of the Maturity Index, Mar. Ecol.-Prog. Ser., 76, 135-142, 1991.

Bongers, T., de Goede, R. G. N., Korthals, G. W., and Yeates, G. W.: Proposed changes of $c-p$ classification for nematodes, Russ. J. Nematol., 3, 61-62, 1995.

Braeckman, U., Vanaverbeke, J., Vincx, M., van Oevelen, D., and Soetaert, K.: Meiofauna Metabolism in Suboxic Sediments: Currently Overestimated, PLoS ONE, 8, e59289, doi:10.1371/journal.pone.0059289, 2013.
Cadotte, M. W., Cardinale, B. J., and Oakley, T. H.: Evolutionary history and the effect of biodiversity on plant productivity, $\mathrm{P}$. Natl. Acad. Sci., 105, 17012-17017, 2008.

Cadotte, M. W., Cavender-Bares, J., Tilman, D., and Oakley, T. H.: Using phylogenetic, functional and trait diversity to understand patterns of plant community productivity, PLoS ONE, 4, e5695, doi:10.1371/journal.pone.0005695, 2009.

Cadotte, M. W., Carscadden, K., and Mirotchnick, N.: Beyond species: functional diversity and the maintenance of ecological processes and services, J. Appl. Ecol., 48, 1079-1087, 2011.

Cardinale, B. J., Nelson, K., and Palmer, M. A.: Linking species diversity to the functioning of ecosystems: on the importance of environmental context, Oikos, 91, 175-183, 2000.

Chown, S. and Gaston, K.: Patterns in procellariiform diversity as a test of species-energy theory in marine systems, Evol. Ecol. Res., 1, 365-373, 1999.

Clarke, K. and Gorley, R.: PRIMER v6: User Manual/tutorial, Primer-E Ltd., Plymouth, 2006.

Clarke, K. R. and Warwick, R. M.: A further biodiversity index applicable to species lists: variation in taxonomic distinctness, Mar. Ecol.-Prog. Ser., 216, 265-278, 2001a.

Clarke, K. and Warwick, R.: Change in marine communities: an approach to statistical analysis and interpretation, Plymouth Marine Laboratory: PRIMER-E Ltd., 2001b.

Corliss, B. H., Brown, C. W., Sun, X., and Showers, W. J.: Deepsea benthic diversity linked to seasonality of pelagic productivity, Deep-Sea Res. Pt. I, 56, 835-841, 2009.

Danovaro, R., Gambi, C., Dell'Anno, A., Corinaldesi, C., Fraschetti, S., Vanreusel, A., Vincx, M., and Gooday, A. J.: Exponential decline of deep-sea ecosystem functioning linked to benthic biodiversity loss, Curr. Biol., 18, 1-8, 2008a.

Danovaro, R., Gambi, C., Lampadariou, N., and Tselepides, A.: Deep-sea nematode biodiversity in the Mediterranean basin: testing for longitudinal, bathymetric and energetic gradients, Ecography, 31, 231-244, 2008b.

Danovaro, R., Bianchelli, S., Gambi, C., Mea, M., and Zeppilli, D.: alpha-, beta-, gamma-, delta- and epsilon-diversity of deepsea nematodes in canyons and open slopes of Northeast Atlantic and Mediterranean margins, Mar. Ecol.-Prog. Ser., 396, 197-209, 2009a.

Danovaro, R., Canals, M., Gambi, C., Heussner, S., Lampadariou, N., and Vanreusel, A.: Exploring benthic biodiversity patterns and hotspots on European margin slopes, Oceanography, 22, 1625, 2009 b.

Danovaro, R., Company, J. B., Corinaldesi, C., D’Onghia, G., Galil, B., Gambi, C., Gooday, A. J., Lampadariou, N., Luna, G. M., Morigi, C., Olu, K., Polymenakou, P., Ramirez-Llodra, E., Sabbatini, A., SardÃ, F., Sibuet, M., and Tselepides, A.: Deep-sea biodiversity in the Mediterranean Sea: the known, the unknown, and the unknowable, Plos One, 5, e11832, doi:10.1371/journal.pone.0011832, 2010.

De Bovée, F. and Labat, J.: A simulation model of a deep meiobenthic compartment: a preliminary approach, Mar. Ecol., 14, 159173, 1993.

De Ley, P., Decraemer, W., and Abebe, E.: Introduction: summary of present knowledge and research addressing the ecology and taxonomy of freshwater nematodes, in: Freshwater nematodes: ecology and taxonomy, vol. 1, edited by: Abebe, E., Andrassy, I., and Traunspurger, W., CABI publishing, 2006. 
De Mesel, I., Derycke, S., Swings, J., Vincx, M., and Moens, T.: Influence of bacterivorous nematodes on the decomposition of cordgrass, J. Exp. Mar. Biol. Ecol., 296, 227-242, 2003.

De Mesel, I., Derycke, S., Swings, J., Vincx, M., and Moens, T.: Role of nematodes in decomposition processes: Does withintrophic group diversity matter?, Mar. Ecol.-Prog. Ser., 321, 157166, 2006.

Díaz, S. and Cabido, M.: Vive la différence: plant functional diversity matters to ecosystem processes, Trends Ecol. Evol., 16, 646-655, 2001.

Dormann, C. F., McPherson, J. M., B. Araújo, M., Bivand, R., Bolliger, J., Carl, G., G. Davies, R., Hirzel, A., Jetz, W., Daniel Kissling, W., Kühn, I., Ohlemüller, R., R. Peres-Neto, P., Reineking, B., Schröder, B., M. Schurr, F., and Wilson, R.: Methods to account for spatial autocorrelation in the analysis of species distributional data: a review, Ecography, 30, 609-628, 2007.

Etter, R. J. and Grassle, J. F.: Patterns of species diversity in the deep sea as a function of sediment particle size diversity, Nature, 360, 576-578, 1992.

Fox, J. and Weisberg, S.: An R Companion to Applied Regression, Sage, 2011.

Glover, A., Smith, C., Paterson, G., Wilson, G., Hawkins, L., and Sheader, M.: Polychaete species diversity in the central Pacific abyss: local and regional patterns, and relationships with productivity, Mar. Ecol.-Prog. Ser., 240, 157-170, 2002.

Gooday, A., Bett, B., Jones, D. O. B., and Kitazato, H.: The influence of productivity on abyssal foraminiferal biodiversity, Mar. Biodivers., 42, 415-431, 2012.

Gravel, D., Bell, T., Barbera, C., Combe, M., Pommier, T., and Mouquet, N.: Phylogenetic constraints on ecosystem functioning, Nature, 3, 1117, doi:10.1038/ncomms2123, 2012.

Gray, J.: Species richness of marine soft sediments, Mar. Ecol.Prog. Ser., 244, 285-297, 2002.

Heip, C., Vincx, M., and Vranken, G.: The ecology of marine nematodes, Oceanogr. Mar. Biol. Ann. Rev., 23, 399-489, 1985.

Hiddink, J. G., Wynter Davies, T., Perkins, M., Machairopoulou, M., and Neill, S. P.: Context dependency of relationships between biodiversity and ecosystem functioning is different for multiple ecosystem functions, Oikos, 118, 1892-1900, 2009.

Hooper, D. U., Solan, M., Symstad, A., Díaz, S., Gessner, M., Buchmann, N., Degrange, V., Grime, P., Hulot, F., and MermillodBlondin, F.: Species diversity, functional diversity and ecosystem functioning, in: Biodiversity and Ecosystem Functioning: Syntheses and Perspectives, vol. 17, edited by: Loreau, M., Naeem, S., and Inchausti, P., 195-208, Oxford University Press, 2002.

Jensen, P.: Measuring carbon content in nematodes, Helgolander Meeresun., 38, 83-86, 1984.

Lambshead, P. J. D. and Boucher, G.: Marine nematode deep-sea biodiversity - hyperdiverse or hype?, J. Biogeogr., 30, 475-485, 2003.

Lambshead, P. J. D., Tietjen, J., Ferrero, T., and Jensen, P.: Latitudinal diversity gradients in the deep sea with special reference to North Atlantic nematodes, Mar. Ecol.-Prog. Ser., 194, 159-167, 2000 .

Lambshead, P. J. D., Brown, C. J., Ferrero, T. J., Mitchell, N. J., Smith, C. R., Hawkins, L. E., and Tietjen, J.: Latitudinal diversity patterns of deep-sea marine nematodes and organic fluxes: a test from the central equatorial Pacific, Mar. Ecol.-Prog. Ser., 236, 129-135, 2002.
Lawton, J. H.: What Do Species Do in Ecosystems?, Oikos, 71, 367-374, 1994.

Leduc, D., Rowden, A. A., Probert, P. K., Pilditch, C. A., Nodder, S. D., Vanreusel, A., Duineveld, G. C. A., and Witbaard, R.: Further evidence for the effect of particle-size diversity on deep-sea benthic biodiversity, Deep-Sea Res. Pt. I, 63, 164-169, 2011.

Leduc, D., Rowden, A. A., Bowden, D. A., Probert, P. K., Pilditch, C. A., and Nodder, S. D.: Unimodal relationship between biomass and species richness of deep-sea nematodes: implications for the link between productivity and diversity, Mar. Ecol.Prog. Ser., 454, 53-64, 2012a.

Leduc, D., Rowden, A., Bowden, D., Nodder, S., Probert, P., Pilditch, C., Duineveld, G., and Witbaard, R.: Nematode beta diversity on the continental slope of New Zealand: spatial patterns and environmental drivers, Mar. Ecol.-Prog. Ser., 454, $37-$ $52,2012 b$.

Leira, M., Chen, G., Dalton, C., Irvine, K., and Taylor, D.: Patterns in freshwater diatom taxonomic distinctness along an eutrophication gradient, Freshwater Biol., 54, 1-14, 2009.

Levin, L. A., Etter, R. J., Rex, M. A., Gooday, A. J., Smith, C. R., Pineda, J., Stuart, C. T., Hessler, R. R., and Pawson, D.: Environmental influences on regional deep-sea species diversity, Annu. Rev. Ecol. Syst., 32, 51-93, 2001.

Loreau, M.: Biodiversity and ecosystem functioning: recent theoretical advances, Oikos, 91, 3-17, 2000.

Lutz, M. J., Caldeira, K., Dunbar, R. B., and Behrenfeld, M. J.: Seasonal rhythms of net primary production and particulate organic carbon flux to depth describe the efficiency of biological pump in the global ocean, J. Geophys. Res.-Oceans, 112, C10011, doi:10.1029/2006jc003706, 2007.

Mason, N. W. H., Mouillot, D., Lee, W. G., and Wilson, J. B.: Functional richness, functional evenness and functional divergence: the primary components of functional diversity, Oikos, 111, 112118, 2005.

McClain, C. R., Allen, A. P., Tittensor, D. P., and Rex, M. A.: Energetics of life on the deep seafloor, P. Natl. Acad. Sci. USA, 109, 15366-15371, 2012.

Menot, L., Sibuet, M., Carney, R. S., Levin, L. A., Rowe, G. T., Billett, D. S. M., Poore, G., Kitazato, H., Vanreusel, A., Galéron, J., Lavrado, H. P., Sellanes, J., Ingole, B., and Krylova, E.: New Perceptions of Continental Margin Biodiversity, in: Life in the World's Oceans, edited by: McIntyre, A. D., 79-102, WileyBlackwell, 2010.

Messier, J., McGill, B. J., and Lechowicz, M. J.: How do traits vary across ecological scales? A case for trait-based ecology, Ecol. Lett., 13, 838-848, 2010.

Moens, T., dos Santos, G. A. P., Thompson, F., Swings, J., FonsêcaGenevois, V., Vincx, M., and De Mesel, I.: Do nematode mucus secretions affect bacterial growth?, Aquat. Microb. Ecol., 40, $77-$ 83, 2005.

Mouillot, D., Gaillard, S., Aliaume, C., Verlaque, M., Belsher, T., Troussellier, M., and Dochi, T.: Ability of taxonomic diversity indices to discriminate coastal lagoon environments based on macrophyte communities, Ecol. Indic., 5, 1-17, 2005.

Moya-Laraño, J. and Corcobado, G.: Plotting partial correlation and regression in ecological studies, Web Ecol., 8, 35-46, 2008.

Muthumbi, A., Vanreusel, A., and Vincx, M.: Taxon-related diversity patterns from the continental shelf to the slope: a case study on nematodes from the Western Indian Ocean, Mar. Ecol., 32, 
453-467, 2011.

Naeem, S. and Wright, J. P.: Disentangling biodiversity effects on ecosystem functioning: deriving solutions to a seemingly insurmountable problem, Ecol. Lett., 6, 567-579, 2003.

Naeem, S., Thompson, L. J., Lawler, S. P., Lawton, J. H., and Woodfin, R. M.: Empirical Evidence that Declining Species Diversity May Alter the Performance of Terrestrial Ecosystems, Philos. T. Roy. Soc. B, 347, 249-262, 1995.

Nakagawa, S. and Schielzeth, H.: A general and simple method for obtaining R2 from generalized linear mixed-effects models, Method. Ecol. Evol., 4, 133-142, 2013.

O'Hara, T. D. and Tittensor, D. P.: Environmental drivers of ophiuroid species richness on seamounts, Mar. Ecol., 31, 26-38, 2010.

Pape, E., Jones, D. O. B., Manini, E., Bezerra, T. N., and Vanreusel, A.: Benthic-Pelagic Coupling: Effects on Nematode Communities along Southern European Continental Margins, edited by: Ferse, S. C. A., PLoS ONE, 8, e59954, doi:10.1371/journal.pone.0059954, 2013.

Pereira, H. M., Leadley, P. W., Proença, V., Alkemade, R., Scharlemann, J. P. W., Fernandez-Manjarrés, J. F., Araújo, M. B., Balvanera, P., Biggs, R., Cheung, W. W. L., Chini, L., Cooper, H. D., Gilman, E. L., Guénette, S., Hurtt, G. C., Huntington, H. P., Mace, G. M., Oberdorff, T., Revenga, C., Rodrigues, P., Scholes, R. J., Sumaila, U. R., and Walpole, M.: Scenarios for Global Biodiversity in the 21st Century, Science, 330, 1496-1501, 2010.

Petchey, O. L., Hector, A., and Gaston, K. J.: How do different measures of functional diversity perform?, Ecology, 85, 847-857, 2004.

Pike, J., Bernhard, J. M., Moreton, S. G., and Butler, I. B.: Microbioirrigation of marine sediments in dysoxic environments: Implications for early sediment fabric formation and diagenetic processes, Geology, 29, 923-926, 2001.

Pinheiro, J. and Bates, D.: Mixed-Effects Models in S and S-PLUS, Springer, 2000.

Pinheiro, J., Bates, D., and DebRoy, S.: nlme: Linear and Nonlinear Mixed Effects Models, R package version 3.1-105, 2012.

Plant, R. E.: Spatial Data Analysis in Ecology and Agriculture Using R, CRC Press, 2012.

Quintana, X. D., Brucet, S., Boix, D., López-Flores, R., Gascón, S., Badosa, A., Sala, J., Moreno-Amich, R., and Egozcue, J. J.: A non-parametric method for the measurement of size diversity, with emphasis on data standardisation, Limnol. Oceanogr.Methods, 6, 75-86, 2008.

R Core Team: R: A Language and Environment for Statistical Computing, R Foundation for Statistical Computing, Vienna, Austria, available at: http://www.R-project.org/, 2012.

Reiss, J., Bridle, J. R., Montoya, J. M., and Woodward, G.: Emerging horizons in biodiversity and ecosystem functioning research, Trends Ecol. Evol., 24, 505-514, 2009.

Revelle, W.: psych: procedures for Psychological, Psychometric, and Personality Research, available at: http://personality-project. org/r/psych.manual.pdf, 2012.

Rex, M. A. and Etter, R. J.: Deep-Sea Biodiversity: Pattern and Scale, Harvard University Press, 2010.

Riemann, F. and Helmke, E.: Symbiotic relations of sedimentagglutinating nematodes and bacteria in detrital habitats: The enzyme-sharing concept, Mar. Ecol., 23, 93-113, 2002.
Smith, C. R., De Leo, F. C., Bernardino, A. F., Sweetman, A. K., and Arbizu, P. M.: Abyssal food limitation, ecosystem structure and climate change, Trends Ecol. Evol., 23, 518-528, 2008.

Snelgrove, P. V. R. and Butman, C. A.: Animal Sediment Relationships Revisited - Cause Versus Effect, Oceanogr. Mar. Biol., 32, 111-177, 1994.

Soetaert, K., Vanaverbeke, J., Heip, C., Herman, P. M. J., Middelburg, J. J., Sandee, A., and Duineveld, G.: Nematode distribution in ocean margin sediments of the Goban Spur (northeast Atlantic) in relation to sediment geochemistry, Deep-Sea Res. Pt. I, 44, 1671-1683, 1997.

Srivastava, D. S., Cadotte, M. W., MacDonald, A. A. M., Marushia, R. G., and Mirotchnick, N.: Phylogenetic diversity and the functioning of ecosystems, edited by: Mooers, A., Ecol. Lett., 15, 637-648, 2012.

Stachowicz, J., Bruno, J., and Duffy, J.: Understanding the effects of marine biodiversity on communities and ecosystems, Annu. Rev. Ecol. Syst., 38, 739-766, 2007.

Stuart, C. T., Rex, M., and Etter, R. J.: Large-scale spatial and temporal patterns of deep-sea benthic species diversity, in: Ecosystems of the deep oceans, edited by: Tyler, P., 295-311, 2003.

Tecchio, S., Ramirez-Llodra, E., Sarda, F., Company, J. B., Palomera, I., Mecho, A., Pedrosa-Pamies, R., and Sanchez-Vidal, A.: Drivers of deep Mediterranean megabenthos communities along longitudinal and bathymetric gradients, Mar. Ecol.-Prog. Ser., 439, 181-219, 2011.

Tittensor, D. P., Rex, M. A., Stuart, C. T., McClain, C. R., and Smith, C. R.: Species-energy relationships in deep-sea molluscs, Biol. Lett., 7, 718-722, doi:10.1098/rsbl.2010.1174, 2011.

Tselepides, A., Papadopoulou, K.-N., Podaras, D., Plaiti, W., and Koutsoubas, D.: Macrobenthic community structure over the continental margin of Crete (South Aegean Sea, NE Mediterranean), Progr. Oceanogr., 46, 401-428, 2000.

Tyler, P. A. (Ed.): The peripheral deep seas, in Ecosystems of the World, 261-293, Elsevier, Amsterdam, 2003.

Vellend, M., Cornwell, W., Magnuson-Ford, K., and Mooers, A. $\varnothing .:$ Measuring phylogenetic biodiversity, in: Biological diversity: Frontiers in measurement and assessment, vol. 14, edited by: Magurran, A. and McGill, B., 194-207, Oxford University Press, Oxford, UK, 2010.

Warwick, R. M. and Clarke, K. R.: New "biodiversity" measures reveal a decrease in taxonomic distinctness with increasing stress, Mar. Ecol.-Prog. Ser., 129, 301-305, 1995.

Warwick, R. M. and Clarke, K. R.: Taxonomic distinctness and environmental assessment, J. Appl. Ecol., 35, 532-543, 1998.

Weiher, E.: A primer of trait and functional diversity, in: Biological diversity: Frontiers in measurement and assessment, vol. 13 , edited by: Magurran, A. and McGill, B., 175-193, Oxford University Press, Oxford, 2011.

Wickham, H.: ggplot2: Elegant Graphics for Data Analysis, Springer, New York, 2009.

Wieser, W.: Die Beziehung zwischen Mundhöhlengestalt, Ernährungsweise und Vorkommen bei freilebenden marinen Nematoden, Eine ökologisch-morphologische Studie, Ark. Zool., 4, 439-483, 1953.

Xu, H., Jiang, Y., Al-Rasheid, K. A. S., Al-Farraj, S. A., and Song, W.: Application of an indicator based on taxonomic relatedness of ciliated protozoan assemblages for marine environmental assessment, Environ. Sci. Pollut. Res., 18, 1213-1221, 2011. 
Zar, J. H.: Biostatistical Analysis, 5th Edn., Prentice Hall, New Jersey, 2010.
Zuur, A. F., Ieno, E. N., and Elphick, C. S.: A protocol for data exploration to avoid common statistical problems, Method. Ecol. Evol., 1, 3-14, 2010. 